\title{
Study of incident water hammer in an engineering loop under two-phase flow experiment
}

\author{
R.K.Singh, S.K.Sinha A.Rama Rao \\ Vibration Laboratory Section \\ Reactor Engineering Division \\ Bhabha Atomic Research Centre \\ Mumbai, India
}

Keywords: Water hammer, steam, water, engineering loop, superheat

\section{Abstract}

Water hammer can occur in case of an inflow of sub-cooled water into pipes or other parts of the equipment filled with steam or steam-water mixture. The shock loading due to dynamic pressure during water hammer induces high stresses in the walls of piping especially in the bends. These stresses are not understood completely. The lack of enough experimental data is a major obstacle for validation of codes on fluid-structure interaction problems. A study was carried out to analyse real life incident of water hammer wherein an attempt was made to recreate water hammer involving steam water interaction in an instrumented engineering loop to capture pressure, temperature, flow rate and fluid levels in the loop. The arrival time of multiple shocks and the time lag between them have been examined in the paper with the support of energy balance equation for variable flow processes.

\section{Introduction}

Water hammer is a common phenomenon when sub-cooled water flow in pipes or other containers filled with steam or steam-water mixture. They also appear as the consequence of fast closing or opening actions of valve or break in the pipelines conveying single or two-phase flow. In the latter case, shock waves are generated. In all the cases however, strong dynamic stresses are induced in the wall of the closed system or equipment. The influence of the fluid-structure interaction and the shock loads on the piping and supporting structures is not completely understood. In case of dynamic loads caused by the pressure wave, the stresses in the walls of pipe especially on the bends are very different from the stresses caused by static loading. The lack of experimental data obtained at welldefined geometric boundary conditions is a significant obstacle for validation of codes on fluidstructure interaction problems. Furthermore, up to now the feedback on structural deformations caused by fluid mechanics has not been fully implemented in the existing codes.

Two incident of loud sound, with in a span of four months was reported by operators of a full-scale engineering loop erected especially for carrying out experiments on loss of coolant accident and natural circulation. The over all size of the loop being too large, it was not possible to pin point exact location of the sound. Besides, there was no reported major deviation in the loop operating 
parameters. As the loop was required to cater for large number of engineering experiments and in order to meet the safety regulation, a decision was taken to instrument the loop with vibration and shock transducers and capture sound wherever it happens in the loop. The operating parameters of the loop were closely studied and all possible combinations that could lead to loud sound were listed for execution.

This paper presents the investigation carried out to locate and quantify the source of loud noise in the loop so that the loop could be operated without violating safety knowingly and unknowingly.

\section{The Integrated Test Loop (ITL)}

Figure 1 shows only the relevant portion of ITL even though it has many more functional sub-loops and systems. The loop mainly consists of a vertical fuel channel simulator (FCS), steam drum (SD), down comer, header, feeder and riser. The FCS is made of 54 electrically heated fuel rods cluster [1]. The SD situated above FCS is designed with all the internals like baffle plates, feed water sparger and active shut down cooler. The loop simulates the elevation, pressure, temperature, velocity and time scales of prototype to carry out study on thermal hydraulic issues of natural circulation of main heat transport system (MHTS). The heat sink for the test facility is provided in the form of a secondary coolant circuit comprising of jet condenser, pool boiling coolers and feed pump. The design pressure and temperature of the loop are 100 bars and $315 \mathrm{deg}$ centigrade. The component and piping in the loop are designed as per ASME Boiler and pressure vessel code section VIII division I. Material of construction of entire MHTS piping is SS316L. During the loop in operation, when the heater power is put on, the water temperature in FCS increases corresponding with the pressure maintained in the loop by a startup boiler system. The hot water moves in the tail pipe and reaches the steam drum. The length of tail pipe is more than 35 meters and the steam drum is 1 meter diameter. In the steam drum, the steam separates from water by gravity separation. The steam when let out, flows down to jet condenser where it encounters jet of sub-cooled water and condenses. The condensed water is pumped back into the steam drum. From lower bottom of the steam drum, the down comer (26 meters) conducts hot water to a header and from header the water is fed to FCS through a feeder (16 meters). A separate loop feeds sub cooled water to jet condenser. A pool boiler connected in this circuit helps in maintaining spray water temperature. 


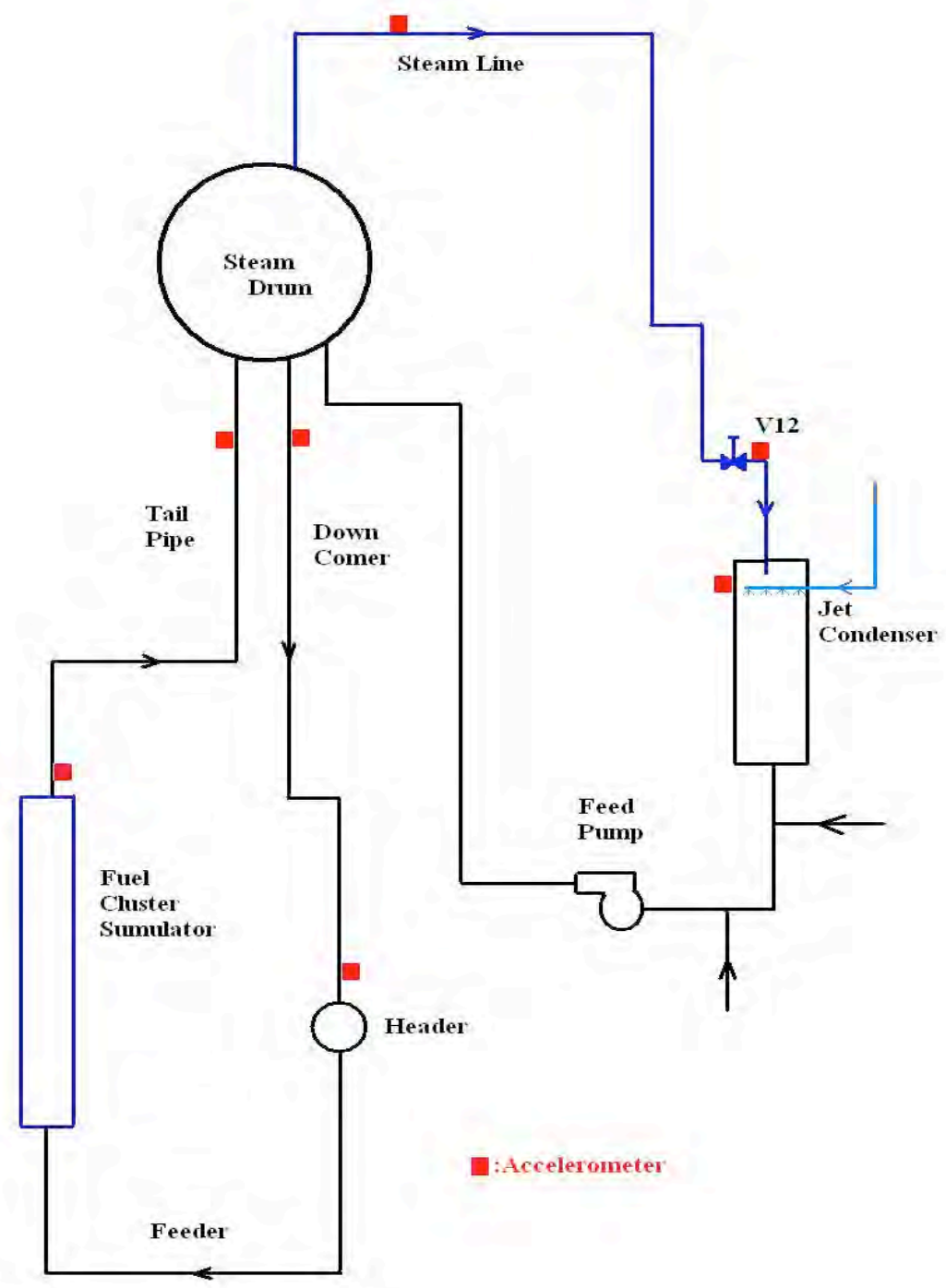

Figure 1 Schematic of Integral Test Loop

\section{Incident of Loud noise}

In early 2006, when the loop was in operation at $2 \%$ power (52 KWth) for shut down cooling experiments; the operators heard a loud sound. The heaters of FCS were switched of and the loop was brought to low temperature and pressure. Not being able to pin point the reason for unusual noise, the loop was restarted and operation continued under similar operating condition. After about a week of operation, the loud sound was again heard. After confirming the incident with all the crewmembers of the loop, it was decided to investigate the source and location of loud noise. 


\subsection{Possible mechanism}

ITL being a natural circulation loop, with the presence of steam and water in the system, three possible mechanisms were considerer.

- Water hammer due to fall of big water slug in the tail pipe.

- Condensation induced water hammer in the steam line. [2], [4]

- Water hammer due to sudden condensation of steam in the jet condenser.

In the first mechanism, due to certain length of tail pipe being laid horizontal before running vertical up to SD, possibility of big water slug falling from SD into the tail pipe was considered. It found true this would lead to thorough redesign of piping and piping layout in the loop.

In the second mechanism, rushing of steam into the steam line and mixing with condensate trapped in the steam line was considered. On many locations on the steam line, the thermal isolation was partially out of place, which could lead to heat loss and potential location for accumulation of condensate. If this was found true, the steam line would be required to be fitted with drainpipe or steam traps.

In the third mechanism, sudden condensation of steam in the jet condenser was considered. If found true, then sub cool spray water temperature and flow rate of the spray water was to be corrected.

To check the possibility of any or all the mechanism to be present in the system, the loop was extensively instrumented with shock and vibration transducers.

\section{Additional Instruments}

Nine accelerometers were installed on the loop and supporting civil structures to enable capturing of the incident of water hammer at any location in the loop. The locations were

- Down comer top $10^{\text {th }}$ floor below SD

- Tail pipe top $10^{\text {th }}$ floor below SD

- Steam line $10^{\text {th }}$ floor

- Steam line $6^{\text {th }}$ floor

- Jet condenser $4^{\text {th }}$ floor

- Down comer bottom $2^{\text {nd }}$ floor

- Tail pipe bottom $2^{\text {nd }}$ floor

- ITL civil building in the jet condenser floor in East-West and North-South direction

The civil structure was instrumented to estimate the amplitude of shock and assess the safety of the building. In addition to vibration, all the loop parameters were connected to a data acquisition system. The selected loop parameters were, SD temperature, water level pressure and feed flow rate. JC temperature, water level and spray flow rate and FCS power and temperature. 


\section{Loop Operation}

To examine the phenomenon of big water slug falling in the tail pipe, the loop was operated at 200 KW heater power and all the parameters adjusted to 60 bar loop pressure. From $200 \mathrm{KW}$, the power was brought to zero (heater switched off) and again taken to $200 \mathrm{KW}$. There was no incident of water hammer in the MHT system. Different crew repeated this process several times during different time. No loud sound was heard.

Next, the feed flow into the steam drum was increased from lower range to upper range to examine if the water hammer can happen in steam drum due to mixing of relatively low temperature feed water with hot water in steam drum. There was no incident of loud sound recorded from any point of the loop.

Next, the steam line was opened for the steam to flow from SD to JC and spray water flow was started. The spray water temperature at the start of spray was $43 \mathrm{deg}$ centigrade and the flow rate adjusted 100 LPM. With in a delay of 2 minutes, a series of five shocks were recorded one after the other. Every subsequent shock was felt with increasing intensity. After the $5^{\text {th }}$ shock, the JC spray was stopped and the loop was brought to zero power.

\section{Signal analysis of water hammer}

Figure 2 shows the vibration signal of the five-water hammer measured on JC. Figure $3 \& 4$ shows the trend of pressure and temperature in JC. The fall and rise of the pressure in the jet condenser takes place within 3 seconds for each shock. The fall in pressure is due to sudden condensation of steam and the recovery is due to additional flow of high-pressure steam from SD to JC. The trend of JC temperature also shows a fall during every water hammer and the lowest temperature in each fall decides the lowest pressure in jet condenser.

The acceleration value shows an increase for every shock indicating increased severity. If the jet condenser spray had not been stopped after the $5^{\text {th }}$ shock, further shock could have been more severe and damaging. The experiment of recreating water hammer in ITL clearly indicated JC as the location of water hammer. It was later identified that the spray flow rate meter was faulty and operations adjusted the flow on trial and error basis. It was construed that, operators may have inadvertently adjusted the flow to a value more than intended to keep the parameters of secondary circuit as per instruction manual. 


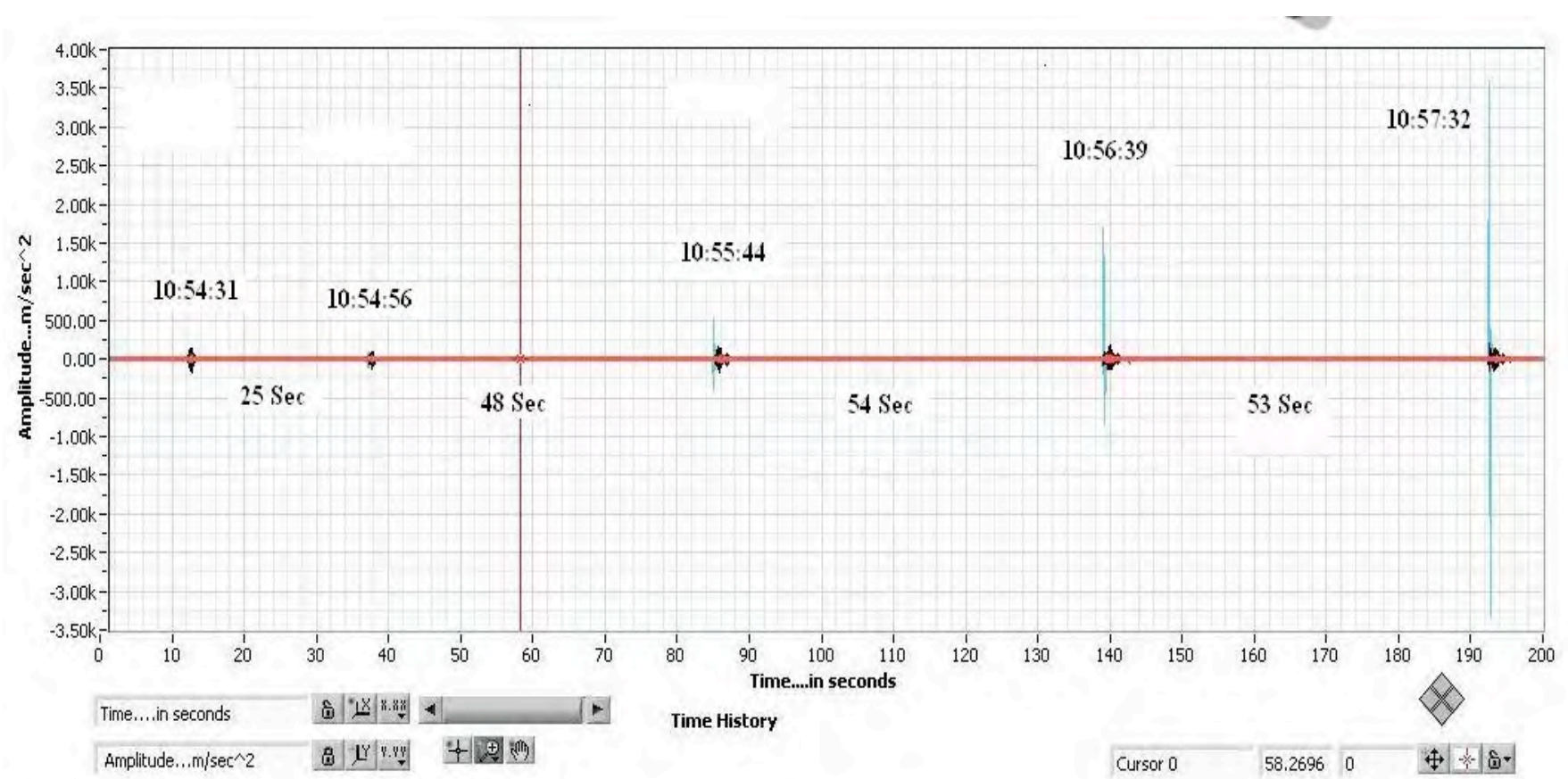

Figure 2 Shock pulses of water hammer

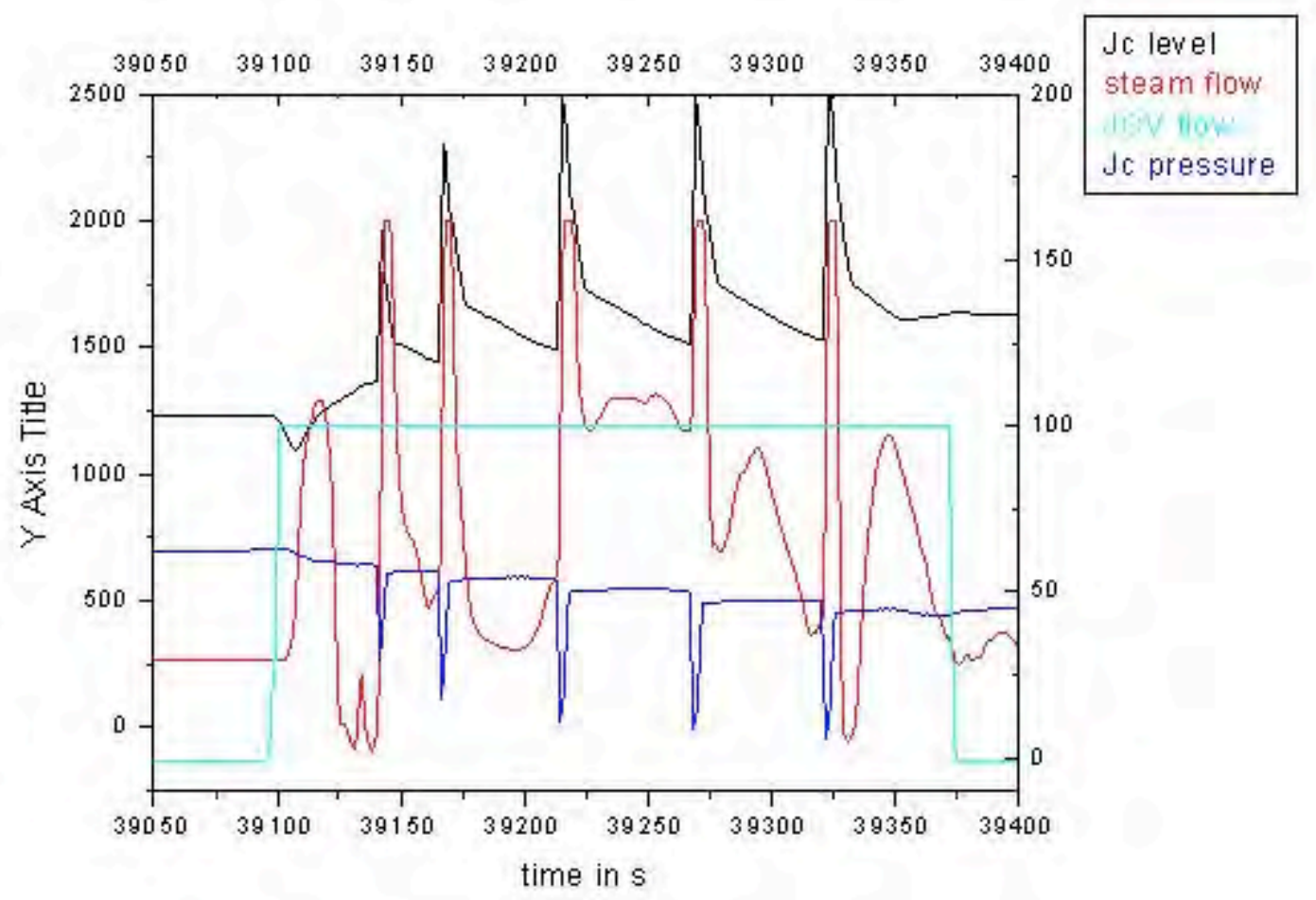

Figure 3 Fluctuations of Pressure and Temperature in jet condenser 


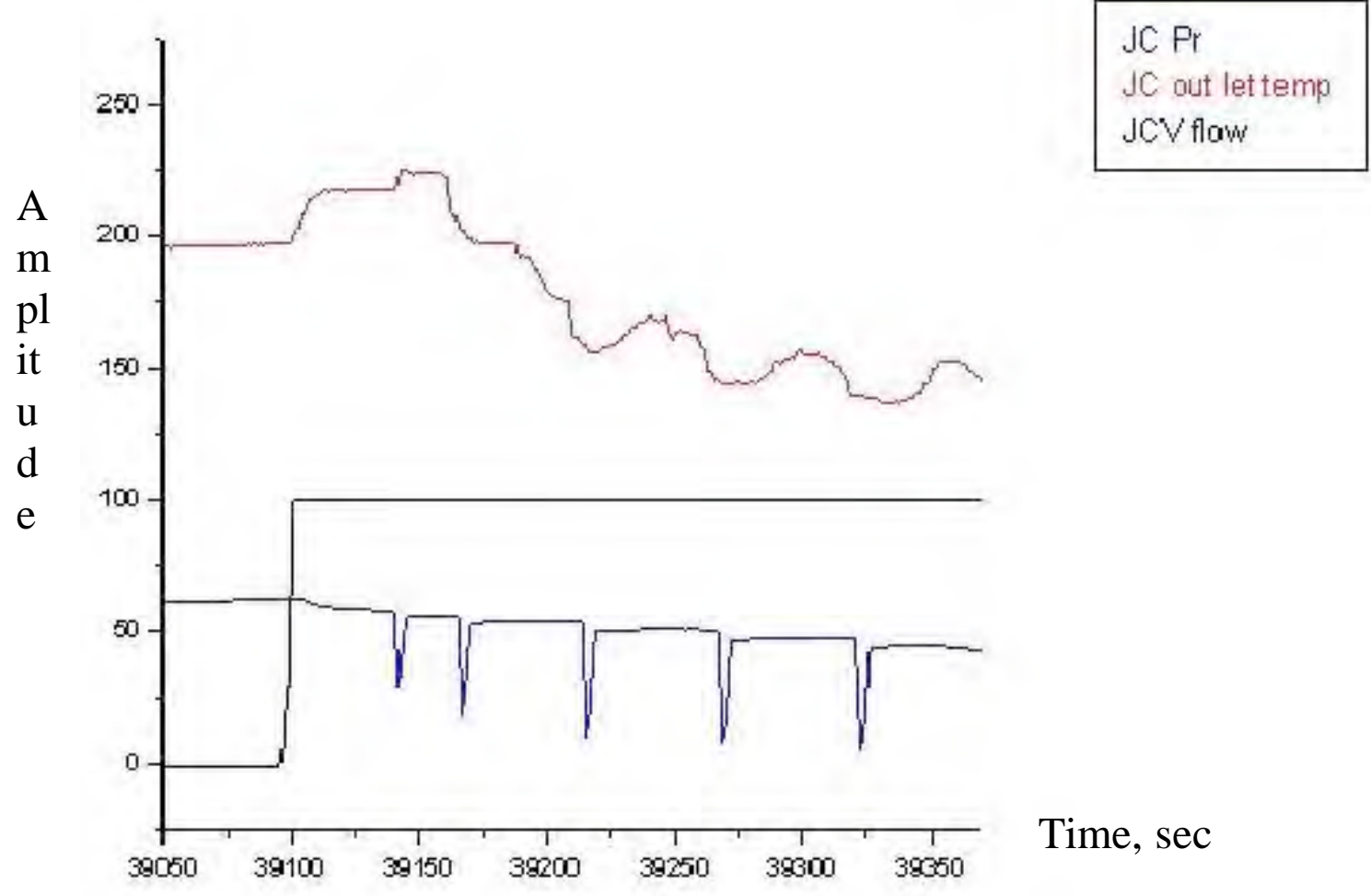

Figure 4 Jet condenser flow characteristics

\section{Time lag analysis}

As seen in Figure 2, 3 and 4 there is varying time lag between the occurrences of the five shock waves due to water hammer in JC. They varied from 25 to 50 seconds. The question was what governed the arrival time of the five shocks. The steam coming to JC was continuous and spray water into JC spray was also continuous. It can be seen in the figure that the pressure in jet condenser does not change much between the events once it recovers from sudden drop. The role of super heat in the steam on arrival of water hammer was analyzed. For this the amount of super heat present in steam and what will be the time required to remove the super heat from the steam and recreate the condition conductive for the next events is evaluated. This is explained in the next Para.

\section{Level of Superheat}

Due to spray cooling, steam inside the jet condenser condenses very fast and so the pressure drops rapidly. As the steam drum is connected to the jet condenser, the steam drum pressure also decreases. As the volume of SD is large, it always remains in saturated condition and so huge amount of steam is generated. This steam naturally flows towards JC. This flow of steam pressurizes $\mathrm{JC}$ and super heats the steam. As heat transfer coefficient of super heated steam is several times lower than condensation of saturated steam, the time required to remove heat from super heated steam is more. The time required to remove the heat from super heated steam depends on the amount of super heat present in JC. 
For quantifying the super heat, energy balance equation for variable flow processes is used as below [3].

$\frac{\mathrm{d}}{\mathrm{dt}}\left(\mathrm{m}_{\mathrm{JC}} \mathrm{u}_{\mathrm{JC}}\right)=\frac{\mathrm{dm}}{\mathrm{dt}}\left(\mathrm{h}_{\text {input }}+\frac{1}{2} \mathrm{v}_{\text {input }}^{2}\right)-\mathrm{Q}_{\text {loss }}-\mathrm{W}_{\text {shaft }}$

The above equation means energy accumulated in JC is equal to energy flowing inside JC minus the heat loss. As there is no work done by any shaft $\mathrm{W}_{\text {shaft }}=0$, and as JC is well insulated so $\mathrm{Q}_{\text {loss }}=0$.

Now the heat balance between steam drum and jet condenser can be given as

$\mathrm{h}_{\mathrm{SD}}=\mathrm{h}_{\text {input }}+\frac{1}{2} \mathrm{v}_{\text {input }}^{2}$

This makes the energy balance equation as

$\frac{\mathrm{d}}{\mathrm{dt}}\left(\mathrm{m}_{\mathrm{JC}} \mathrm{u}_{\mathrm{JC}}\right)=\frac{\mathrm{dm}_{\mathrm{JC}}}{\mathrm{dt}} \mathrm{h}_{\mathrm{SD}}$

For a sample calculation, initial and final pressure in JC was taken as 10 bars and 50 bars respectively. Initial (at 10 bars) mass in $\mathrm{JC}$ was taken $\mathrm{m}_{\mathrm{i}}$ and final mass as $\mathrm{m}_{\mathrm{f}} \cdot \mathrm{h}_{\mathrm{SD}}$ is enthalpy of saturated steam at 50 bars. Integrating the final equation from initial to final time the following equation is obtained.

$\mathrm{m}_{\mathrm{f}} \mathrm{u}_{\mathrm{f}}-\mathrm{m}_{\mathrm{i}} \mathrm{u}_{\mathrm{i}}=\int_{0}^{\mathrm{t}_{\mathrm{f}}} \frac{\mathrm{dm}}{\mathrm{dt}} \mathrm{h}_{\mathrm{SD}} \mathrm{dt}$

Dividing equation (4) by $\mathrm{m}_{\mathrm{i}}$ the following is obtained.

$\frac{\rho_{\mathrm{f}}}{\rho_{\mathrm{i}}} \mathrm{u}_{\mathrm{f}}-\mathrm{u}_{\mathrm{i}}=\left(\frac{\rho_{\mathrm{f}}}{\rho_{\mathrm{i}}}-1\right) \mathrm{h}_{\mathrm{SD}}$

Substituting the values for $\mathrm{f}, \mathrm{i}, \mathrm{u}_{\mathrm{i}}, \mathrm{h}_{\mathrm{SD}}$ etc $\mathrm{u}_{\mathrm{f}}$ is obtained equal to $2751 \mathrm{KJ} /{ }^{0} \mathrm{~K}$. The temperature corresponding to 50 bar is $323^{\circ} \mathrm{C}$ whereas the saturation temperature at 50 bar is $263^{0} \mathrm{C}$. This gives super heat of $60^{\circ} \mathrm{C}$ in the steam. The average steam flow needed for pressurizing is approximately 2200 LPM which matches with the measured steam flow from SD to JC.

\section{Time to remove superheat}

The pressure drop occurs in JC due to condensation of steam in one second (pressure drops from 50 to 10 bar in one second). The rate at which the heat is removed from the steam is calculated by taking the condensation heat transfer coefficient given in the JC design report. The typical steps of calculation are given below.

The time to remove superheat from the steam was calculated by taking heat transfer coefficient based on steam side conduction.[5]

For super heat removal from the steam, a spherical shape of water drops is assumed and steam side conduction is considered. So, 
$\mathrm{Q}_{\text {superheat }}=\frac{4 \pi \mathrm{r}_{\mathrm{d}} \mathrm{r}_{\mathrm{b}} \Delta \mathrm{T}}{\mathrm{r}_{\mathrm{d}}-\mathrm{r}_{\mathrm{b}}}$

Here $\mathbf{r}_{\mathbf{d}}$ is radius of liquid drop and $\mathbf{r}_{\mathbf{b}}$ is half of the average distance between two drops. The size of water drop is approximately taken as $0.5 \mathrm{~mm}$, which agrees with size given in design manual. Since $\mathrm{r}_{\mathrm{b}} \gg \mathrm{r}_{\mathrm{d}}$ we can say

$\mathrm{Q}_{\text {superheat }}=4 \pi \mathrm{r}_{\mathrm{d}} \mathrm{r}_{\mathrm{b}} \Delta \mathrm{T}$

Correlation used for condensation calculation is,

$\mathrm{Nu}=2+0.57(\operatorname{Re})^{0.5}(\operatorname{Pr})^{0.33}$

From above equation we can get heat transfer coefficient from $h=\frac{N u k}{D}$

Heat transfer during condensation will be

$\mathrm{Q}_{\text {condensation }}=4 \pi r_{d} r_{b} h \Delta T$ so

$\frac{\mathrm{Q}_{\text {condensation }}}{\mathrm{Q}_{\text {superheat }}}=\mathrm{r}_{\mathrm{d}} \frac{\mathrm{h}}{\mathrm{k}}$

$\mathbf{N u}$ is calculated as 11.36 and hence $\mathbf{h}$ is equal to $2420 \mathrm{Btu} / \mathrm{Hr} \mathrm{ft}^{2}{ }^{0} \mathrm{~F}$. In MKS units $\mathbf{h}$ is equal to 14235.2. $\mathbf{k}$ is steam conductivity. By substituting all values in equation (11) we get

$\frac{\mathrm{Q}_{\text {condensation }}}{\mathrm{Q}_{\text {superheat }}}=222.3$

It shows condensation heat removal rate is approximately 222.3 times of super heat removal rate.

For $60^{\circ} \mathrm{C}$ super heat, time calculated to quench this superheat is found 33 seconds.

The measured time delay between the events as shown in Figure 2 range from 25 to 53 seconds. The variation is basically because of different quantity of steam entering the JC and different pressure range during each event. A close agreement has been arrived at between the calculated and the measured time delay.

\section{Conclusion}

Condition for water hammer was recreated in an engineering loop erected for carrying out thermal hydraulic experiment. The loop was extensively instrumented with vibration and shock transducers to quantify and locate the incident of water hammer. Five shocks of increasing intensity due to water hammer caused by condensation of steam in a jet condenser were recorded. Safe practice of operating the loop without encountering incidence of water hammer in future was identified.

An attempt was made to explain the reason for time delay different between the events through energy balance equation and the time required to quench the quantity of super heat in the steam was estimated.

\section{Acknowledgement}

The multitask work of recreating water hammer in the engineering loop was supported by staff of Engineering Facilities Section of the division. Engineers of Thermal hydraulic section extended all the technical support for the preliminary work of additional instrumentation and data acquisition 
under the guidance of Dr P.K.Vijayan. Director of Reactor Design and Development Group and Head, Reactor Engineering Division encouraged to investigate the incident and minutely followed the development. Authors would like to acknowledge the support received from each one involved in the work.

\section{Reference}

[1] BARC report :Integral test loop scaling philosophy and system description. Report No. BARC/ 2002/E/017 2002

[2] Wayne Kirsner,PE, Condensation - induced. HPAC January 1999

[3] Michacl P. Paidoussis Fluid Structure Interactions. Slender Structures and Axial Flow. Volume 1 \& 2. ISBN 0-12-544360-9 (1998)

[4] Eberhard Altstadt et.al Fluid Structure Interaction Investigations for piping. Wissenschaftlich-Technische Berichte FZR-393. Dec-2003 ISSN 1437-322X

[5] Ki Yong Chei et.al Direct Contact Condensation Heat Transfer Model in RELAP5/ MOD3.2 with/without Non Nondensable Gas for Horizontally Stratified Flow. NED 211(2002) pp139-151 